\title{
The Ambivalence of Promising Technology
}

\author{
Clare Shelley-Egan
}

Received: 26 July 2010 /Accepted: 26 July 2010 /Published online: 17 August 2010

(C) The Author(s) 2010. This article is published with open access at Springerlink.com

\begin{abstract}
Issues of responsibility in the world of nanotechnology are becoming explicit with the emergence of a discourse on 'responsible development' of nanoscience and nanotechnologies. Much of this discourse centres on the ambivalences of nanotechnology and of promising technology in general. Actors must find means of dealing with these ambivalences. Actors' actions and responses to ambivalence are shaped by their position and context, along with strategic games they are involved in, together with other actors. A number of interviews were conducted with industrial actors with the aim of uncovering their ethical stances towards responsible development of nanotechnology. The data shows that standard repertoires of justification of nanotechnological development were used. Thus, the industrial actors fell back on their position and associated responsibilities. Such responses reinforce a division of moral labour in which industrial actors and scientists can focus on the progress of science and technology, while other actors, such as NGOs, are expected to take care of broader considerations, such as ethical and social issues.
\end{abstract}

C. Shelley-Egan $(\bowtie)$

Department of Science, Technology and Policy Studies, University of Twente,

Enschede, Netherlands

e-mail: c.shelleyegan@utwente.nl
Keywords Ambivalences - Division of moral labour . Position and context - 'Responsible development' of nanotechnology $\cdot$ Responsibilities · Strategic games

Discourse on the responsible development of nanoscience and nanotechnologies starts with the promise of nanoscience and nanotechnology but then centres on ambivalences in nanotechnology, for example, the notion that "size matters". On the one hand, "size matters" in terms of the interesting phenomena and novel effects which occur at the nano-scale. On the other hand, "size matters" with regard to the potential toxicity of nanoparticles. Other ambivalences, such as promises that may turn into hype, apply not only to nanotechnology but to promising technology in general. Such ambivalences generate and definitely fuel discussion, as well as contestation, between proponents and opponents of the promising technology. These are particularly salient in nanotechnology and deserve further consideration.

\section{Ambivalences of Promising}

A traditional individual-based ethics would say that one should not exaggerate but this cannot capture the whole story of ambivalence in promising technology. A technology such as nanotechnology needs promises, including some exaggeration, to persuade target audiences. It is the only way to mobilise resources to actually realise the promise. Thus, actors have to 
participate in the strategic game of promising (sometimes beyond reason).

Current developments in the world of nanotechnology demonstrate the role of position and context and strategic games in promising technology. There is a back-and-forth pattern of ethical argumentation between proponents and opponents of the technology. The arguments put forward by the actors are indicative of their view of what the 'responsible development' of nanotechnology should involve. Some stable distribution of responsibilities (and thus, a division of moral labour) may evolve. This distribution of responsibilities may well be justified and productive but it is primarily the outcome of a struggle, a larger and more distributed version of the struggle that Latour illustrated with the program and anti-program of the hotel manager and the hotel guests in relation to the hotel key [2].

Such positioning and the patterns that are involved have been analysed before; I will offer a brief overview in the next section. What is new for nanotechnology is that such discussions and positioning have become pervasive and that actors have to be articulate about them.

Industrial actors are interesting in this respect, because they are closer to actual applications and their repercussions than scientists. We initiated a discussion around responsible development of nanotechnology in interviews with industrial actors. This was part of the 'Ethics in the Real World' workpackage in the EU-funded DEEPEN (Deepening Ethical Engagement and Participation in Emerging Nanotechnologies) project. $^{1}$ The industrial actors struggled with ambivalences in nanotechnology; their responses to these ambivalences were linked with their position as industrial actors and the particular contexts within which they act. Interestingly, and indicative for the new situation around nanotechnology, their interactions with NGOs influenced how they dealt with ambivalence in nanotechnology.

The repertoires that the industrial actors drew on reflect an 'enactor' perspective; the promise of nanotechnology must be pushed and ethics is seen as a brake on progress. However, they can be more nuanced, as our interview data show. By way of a preface, I offer two vignettes demonstrating strategic use of promises. One

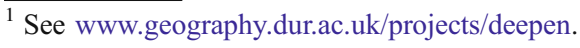

vignette describes the strategic considerations towards hype followed by biotechnologists in the Netherlands in the 1980s, while the other recapitulates the use of promises about embryo research by opponents of the research.

Proponents of a technology are faced with strategic considerations with regard to whether they want to contribute to hype around a technology or be more reasonable in referring to the promise of a technology; these strategies can be combined with different resource mobilisation strategies. Rip and Nederhof [5] observed that these two strategies were pursued by scientific researchers in the Netherlands in the 1980s, in the move towards biotechnology-relevant research. Biochemists and molecular biologists made strong claims especially because they were more removed from actual practices of biotechnology than microbiologists and chemical engineers, who were more modest. As biotechnology was not an essential component of their ongoing research, biochemists and molecular biologists were 're-labelling' $([5], 258)$ their ongoing research, so that they too could join the biotechnology band-wagon and avail of policy funding opportunities.

The promises of proponents of a technology can be strategically used by opponents to undermine their credibility. Mulkay [3] examines some of the rhetorical resources used by opponents and proponents of embryo research during a parliamentary debate in the UK House of Commons in 1990. Both rhetorics 'look into the future and focus on the expected outcomes of scientific research' ([3], 728). Proponents of the research used the rhetoric of hope to make strong claims about the promise of the research, even though the details of the development were as yet unknown. For opponents, the tangible achievements of embryo research to date were judged to be negligible and the rhetoric of fear was used to challenge opponents' claims, transforming them into a 'collection of misleading exaggerations' ([3], 730).

These vignettes demonstrate actors' response to the ambivalence of hype and, in turn, their response to the opportunities of a promising technology (in the first case) and the concerns evoked by a promising technology (in the second case). To continue this discussion, the 'ethics of promising technology' [10] suggests that one should not exaggerate without reason but also that there may well be reasons: 'one has to mobilize resources to be able to realize (materialize) the promises, and has to do so in 
competition with many other claims on such resources' ([10], 18). Moreover, 'one has to claim more than is reasonable, in order to be able to realize what is actually a reasonable claim' ([10], 18). This ambivalence is widely recognised in promising technology. It leads to two different actor strategies: one can choose to sustain the hype or be more modest in presenting the promise of a technology. While there is an immediate opportunistic argument to pursue the hype strategy, there are two arguments against it. As a result of inflated promises, research investment may be directed into unfeasible areas of research, to the detriment of other research communities that could have benefited more from investment, resulting in wasted resources and missed opportunities. The deontological argument highlights the ethics of exaggeration [10].

There is actually a general pattern in the promises and the responses to them. Sparrow [9] and Swierstra and Rip [10] argue that proponents of nanotechnology often try to have it both ways in arguments about the nature and impact of nanotechnologies, describing nanotechnologies as both revolutionary and evolutionary, depending on the discourse surrounding nanotechnologies at the time: 'In arguments about their nature and impact we are simultaneously informed that these are revolutionary technologies with the potential to profoundly change the world and that they merely represent the extension of existing technologies' ([9], 57). This ambivalence is visible in patterns of ethical argumentation about new and emerging science and technology described by Swierstra and Rip [10]. The pattern starts with promises voiced by proponents, claiming major changes, all for the good of mankind, that is, the technology is 'revolutionary'. In response, opponents of the technology who are calling for a cautious approach highlight the novelty of the new technology in order to bring attention to the dearth of knowledge about effects of the new technology. The proponents then face a problem; they had initiated the discussion by stressing the novelty of the technology in order to attract allies and mobilise resources. They are now forced to downplay the novelty of the emerging technology and present it as nothing unusual; what was once termed 'revolutionary' is now toned down to 'business as usual' or 'evolutionary'.

This downplaying of novelty by proponents of the new technology is just one move in the strategic game played between proponents and opponents.
When the capacity to continue with the development of 'revolutionary' nanotechnology is threatened by opponents' concerns, the proponents are forced to present nanotechnology as 'evolutionary' in order to assuage the concerns and fears of opponents. Given the way in which 'revolutionary' or 'evolutionary' nanotechnology is deployed according to the need to hype up or play down nanotechnology in response to opposing voices, it is clear that this ambivalence depends on the particular context in which nanotechnology is discussed.

This form of context-dependence can also manifest itself in the specific qualification of 'revolutionary' or 'evolutionary'. In an interaction between a prominent representative of industry and a leading NGO representative at a seminar on policy-making in nanotechnology, I observed how the notion of 'revolutionary' nanotechnology was given another qualification. The industry representative began her presentation by saying that nanotechnology should be seen as a revolution in quality of life rather than as an industrial revolution. This interpretation of 'revolutionary' differs from the interpretation of 'revolutionary' nanotechnology as 'the next Industrial Revolution' which will profoundly change the world for the better. In correspondence following the meeting, the industry representative told me that the message she wanted to convey was of the great impact of nanotechnology rather than that of an industrial revolution because of the specific view of 'industrial revolution', which is not altogether positive; thus it seemed that the industry representative was cognisant of the need to tailor the notion of 'revolutionary' nanotechnology to suit the particular context. In this context, the opposing discussant was an important factor and the industry representative demonstrated awareness of what kinds of argument might appeal to or even 'win over' the NGO representative. Interestingly, the industry representative had mobilised an argument from 'good life' ethics to argue for the continued development of nanotechnology. This argument is most often used by commentators and critical groups who will sometimes describe a 'good life' and use this as a reference in discussions about a promising technology; on the other hand, proponents of a promising technology often push the promises and fantastic possibilities of a new technology without reflecting on what kind of 'good life' their technology might deliver [10].

The NGO representative then gave a presentation entitled 'There should be a nanotech moratorium' 
during which he asserted that 'nanotechnology is (emphasis added) a major industrial revolution'.

In this interaction, it appears that the NGO representative is also aware of the use of qualifying 'revolutionary' by conceptualising it in terms of 'industrial revolution'. ' His labelling of 'revolutionary' nanotechnology as a 'major industrial revolution' enabled him to use the negative connotation of 'industrial revolution' in a counter strategy to argue for a moratorium on nanotechnology $\mathrm{R} \& \mathrm{D}$. The 'game' of back - and - forth argumentation is visible again.

\section{Positions of Industrialists}

These are general considerations. How do industrial actors manage these ambivalences and tensions when faced with strong claims about the promises of nanotechnology emanating from policy makers and being taken up in society, as well as the emerging discourse about responsible development of nanoscience and nanotechnologies and possible restrictions on unfettered development of nanotechnologies?

We mapped the ethical commitments and patterns of moral argumentation of industrial actors whose company had some involvement in nanotechnology. We interviewed respondents from companies involved in the three main domains in nanotechnology-micro/nanoelectronics, materials and surfaces and bionanotechnology. The respondents came from multinational companies including a chemical company, two semiconductor companies, a beverage and foodstuffs company and a big conglomerate including a food company.

In some sectors, nanotechnology is an enabling technology which delivers new materials and components to help create better devices and systems which provide desired functionalities. In other sectors, nanotechnology just improves performance and sometimes allows new functionalities (e.g. surfaces that repel dirt) but the constitutional effects derive from the system and how it is embedded and used. Still, nanotechnology can lead to major differences because certain thresholds may be passed. For

\footnotetext{
${ }^{2}$ The use of 'industrial revolution' by both proponent and opponent of nanotechnology is an example of 'argumentative association' [4] as cited after Burchell [1]; arguments can be made more or less convincing by associating them, positively or negatively, with other notions, historical practices and so on.
}

example, when RFID (Radio Frequency Identification Devices) becomes cheaper and smaller, thanks to nanotechnology, and thus more widely usable and easier to implant, all products can be traced individually and an "Internet of Things" becomes possible, leading to a view of the implantable and thus "readable" human. All this is yet to come but it is being discussed already and may lead to measures and arrangements [7].

For new materials, it is indicative that chemical firms have developed nanotechnology codes of conduct. They have a good record (cf. Responsible Care program) and think they can meet the credibility pressures. For other domains under the umbrella of nanotechnology, the situation is more complex. Micro-electronics firms have other priorities than responsible development of nanotechnology. In bionanotechnology, companies' first concern is to survive.

The industrial actors we interviewed did not switch from 'revolutionary' to 'evolutionary' but the other way around, from 'evolutionary' to 'revolutionary'. We began the interviews by asking the respondents about their company's involvement in nanotechnology and their stance towards responsible innovation in nanotechnology. ${ }^{3}$ They described nanotechnology as an 'evolution' in their development and responsible innovation in nanotechnology as a normal part of their Corporate Social Responsibility, thus 'business as usual'.

This description of development in nanotechnology as 'business as usual' was evident in the bemused response of a respondent from a chemical company when asked how his company came to be involved in nanotechnology. He replied 'We are a chemical company, so why the question?' He went on to describe nanotechnology as a 'natural step in development' when nanotechnologies are defined as 'the next step to control materials at an ever smaller scale.' In another version of 'business as usual', the respondent from the beverage and foodstuffs company explained that there is already nanotechnology-which is not new-in the food chain.

Nanotechnology was viewed as evolutionary by respondents from both semiconductor companies. One respondent explained that nanotechnology simply represents a solution to a technical problem.

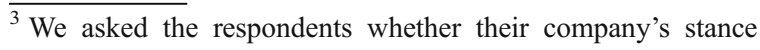
was part of their overall Corporate Social Responsibility or additional to corporate responsibility; we wanted to find out if the industrial actors considered nanotechnology to be 'ethically special'.
} 
In the semiconductor sector, micro-electronics includes more and more nanotechnology in its miniaturisation drive. Thus, for this sector, nanotechnology is not revolutionary; it is the continuation of microtechnology.

The industrialists' use of the 'nothing unusual' argument is general but is articulated differently. The response of the respondents from the chemical company and the beverage and foodstuffs company highlights that there is nothing yet at stake for the companies in terms of having to deal with specific nanotechnologyrelated issues such as ethical, environmental and health and safety issues. Their response emphasised downplaying the promise of nanotechnology; these sectors of industry are aware that nanotechnology evokes certain fears and concerns so they are careful to stress that nanotechnology is nothing new and thus not cause for concern. The semiconductor sector, on the other hand, does not see these concerns as relevant for them, if they are aware of them at all.

When we asked the respondents for their view on calls for a ban on nanotechnology development ${ }^{4}$ nanotechnology became 'revolutionary'-with the exception of the respondents from the semiconductor companies - and could contribute to efforts towards climate protection or to the fight against cancer. This was then linked to an ethical argument against a moratorium on nanotechnology development. ${ }^{5}$

I offer a few quotes to support this diagnosis:

'Nanotechnology would be good for the environment, for energy use, etc. and if you look at nanomedicine-what they talk aboutnobody can be against it... if you design a medicine in such a way that it finds the right place to be released in the body without any additional side-effect' (respondent from the chemical company).

The benefits of nanotechnology in the push towards climate protection were noted by the respondent from a big conglomerate including a food company who felt that a moratorium on

\footnotetext{
${ }^{4}$ In 2003, the ETC Group, a non-governmental environmental organisation, called for a moratorium on the commercial production of new nanomaterials.

${ }^{5}$ Rip [6] argues that proponents of a technology often invoke ethical arguments about their mandate to work towards progress and failure to harness the potential of a new technology is seen as unethical.
}

nanotechnology R\&D would slow down the development of solar cells '...when everybody outside is saying, the single biggest threat to our human species is climate change...'. He added '[The] same applies for preservation of foods in hunger stricken areas'. This respondent continued by making claims of 'ethically responsible' action and said that he considered a moratorium on commercial development of nanotechnology to be itself possibly 'ethically questionable.'

In the last quotes, the 'nothing unusual' argument is inverted; the proponents of the new technology stress the novelty of nanotechnology when defending continuation of its development. This differs from the pattern of moral argumentation described by Swierstra and Rip. In this case proponents of nanotechnology adopt the strategies of opponents - to highlight the novelty of nanotechnology-but for a different cause than that pushed by opponents. Here the novelty argument or revolutionary argument is used in order to defend development of nanotechnology. Thus the respondents use the revolutionary argument when there is something at stake for them as proponents of nanotechnology; in this case it is their right to continue to work on nanotechnology development. There was a clear shift in focus from the technical or the performance aspect-when referring to the evolutionary nature of nanotechnology - to the social problem/solution dichotomy-when pronouncing on the revolutionary potential of nanotechnology. When respondents referred to social issues such as medical treatments and climate change, which are both high on the agenda in discussions in the social sphere, nanotechnology became revolutionary. Positioning nanotechnology as a potential solution to social problems facilitated the call for ongoing development of nanotechnology.

The industrial actors have a prudent approach to the promise of nanotechnology. They realise that it is in their interest to present nanotechnology as 'business as usual' or 'evolutionary' in order to render nanotechnology familiar and therefore harmless. On the other hand, they offer the promise of 'revolutionary' nanotechnology as an argument to let them continue. Such an argument assumes that their audience will want progress (through nanotechnology) and so will be receptive to their claim. NGOs and civil society organisations may, or may not, go along with this. An example is the Friends of the Earth report on agricultural and food 
applications; ${ }^{6}$ while FoE wants improvement of agriculture, the nano route will prejudice precision agriculture as an alternative to the biological/ecological route favoured by FoE.

\section{A Division of Moral Labour}

The ethical arguments of the industrial actors referred to their notion of progress through the development of nanotechnology. Indeed their response to the ambivalence of the nature and impact of nanotechnology was predicated on their need to be allowed to continue with the development of nanotechnology. However, they did not make this kind of argument upfront. This argument emerged when they made claims of 'ethically responsible' action, for instance, the development of organic solar cells to be deployed in the fight against climate change. Thus responsibility was explicitly framed in terms of the development of nanotechnology to meet societal challenges. This then allowed them to turn the stance of NGOs that industry is ethically questionable in its pursuit of nanotechnology back onto the NGOs; if NGOs stop development in nanotechnology, then they are the ones who are unethical.

The ethical arguments which the industrial actors used to justify development in nanotechnology reflect standard repertoires in which scenarios of promise are pushed and ethics is viewed as a brake on progress. These standard repertoires build on the present division of moral labour. Division of moral labour refers to a division of obligations and commitments, as well as to notions regarding who is eligible to be praised or blamed [8]. The present division of moral labour creates a space in which scientists and other technology developers, such as industrial actors, can focus on the progress of science and technology, while other actors (government agencies, NGOs) are expected to look after other considerations, including ethical and social ones.

Indeed the industrial actors' view of the role of NGOs in the responsible development of nanotechnology referred to a division of moral labour. The industrial actors felt that NGOs had the right to ask critical questions and indeed, that somebody should ask questions on behalf of the public. This was reflected in one respondent's view that NGOs are

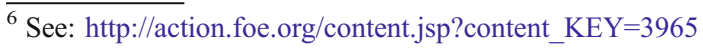

'entitled to their position' even when they call for a moratorium on nanotechnology development.

Another respondent felt that NGOs' concern about nanotechnology is

'...a very good thing, in the sense that there are groups of people who watch the developments and look critically at them, ask questions to make sure that everybody is keen on the balance between opportunities and the potential risks. Well, that's the impression I have. Also, I believe that even the groups that are sort of aware and ask critical questions, my personal impression is that they are also looking for the balance about what is really the issue and only the ones who are very political will make a firm statement like there should be a ban before we know enough'.

Here the respondent introduces a distinction between 'good' NGOs and 'bad' NGOs. This is an enlightened view; there are also industrial actors who are furious over the activities of NGOs. In our interviews, we heard respondents accuse NGOs of being agitators, failing to act in good faith, using misleading information to further their cause and painting different nanotechnologies with the same brush.

\section{In Conclusion}

A division of moral labour is effective when it is accepted and implemented, that is, when it is 'solid'. However, in changing circumstances (which might include changing values, e.g. about precaution or about participation), where responsibilities may have to be redefined, the solidity of the division of labour will become a hindrance rather than a help. It has to be opened up or "melted" down to allow space for new configurations [8]. While the industrial actors' views about NGOs reinforced this division of labour, new configurations in the world of nanotechnology, such as the collaboration between the chemical manufacturing company DuPont and the nonprofit group Environmental Defense, suggest that there is already a move towards redefining responsibilities in the world of nanotechnology.

In 2005, DuPont and Environmental Defense (who could be viewed as adversarial stakeholders) formed a partnership to work together to produce a nano risk 
framework, ${ }^{7}$ aimed at evaluating and addressing potential environmental, health and safety risks of nanomaterials across the entire life cycle of the materials. DuPont evaluated the framework-deemed appropriate by both organisations - using three case studies and published the results in early 2007. Both organisations have issued a call for feedback on the framework and have encouraged companies to adopt the framework. Interestingly, there was a response from a 'civil society labour coalition', ${ }^{8}$ which issued a statement condemning what they called the 'public relations campaign' of DuPont and Environmental Defense. The corporate partnership between DuPont and Environmental Defense may set a precedent for a new kind of interaction between industry and NGOs. On the other hand, the strong response from the civil-society labour coalition reasserted the traditional boundaries and division of moral labour which exist between industry and civil society organisations. At this stage, it is impossible to decide whether the civil-society labour coalition's reaction is conservative in the face of ongoing overall changes, or an indication that such changes are not occurring, and the DuPont-Environmental Defense collaboration is a passing occurrence.

This case shows that operationalisation of 'responsible development' can, and will, be contested because changes in division of moral labour are about politics just as much as they are about ethics. This is visible in my interview data as well, even while there is no action involved. The ambivalences of nanotechnology, and of promising technologies more generally, are not just an intellectual challenge; the evolving strategic games that are played are for real, even if the discourse of responsible development may start as a new 'language game'.

Acknowledgements I gratefully acknowledge productive discussions during the DEEPEN project, important suggestions for the present paper from Arie Rip and Marta Kirejczyk and helpful discussions with Tsjalling Swierstra about ethics. I would like to thank the interviewees for their willingness to share their knowledge and experience with me.

Open Access This article is distributed under the terms of the Creative Commons Attribution Noncommercial License which permits any noncommercial use, distribution, and reproduction in any medium, provided the original author(s) and source are credited.

\section{References}

1. Burchell K (2007) Boundary work, associative argumentation and switching in the advocacy of agricultural biotechnology. Sci Cult 16:49-70

2. Latour B (1991) Technology is society made durable. In: Law $\mathrm{J}$ (ed) A sociology of monsters: essays on power, technology and domination. Routledge, London, pp 103-132

3. Mulkay M (1993) Rhetorics of hope and fear in the great embryo debate. Soc Stud Sci 23:721-742

4. Myerson G, Rydin Y (1996) The language of environment. UCL Press, London

5. Rip A, Nederhof AJ (1986) Between dirigism and laissezfaire: effects of implementing the science policy priority for biotechnology in the Netherlands. Res Policy 15:253-268

6. Rip A (2007) Research choices and directions - in changing contexts. In: Marion Deblonde et al. Nano Researchers Facing Choices. Universitair Centrum SintIgnatius Antwerpen, June 2007, pp 33-48. The Dialogue Series \#10

7. Rip A (2008) De facto governance of nanotechnologies. Preprint of the Proceedings of the Tilburg Institute for Law, Technology and Society (TILT) 'Tilting Perspectives on Technology Regulation' Conference, 10-11 December, 2008

8. Rip A, Shelley-Egan C (2010) Positions and responsibilities in the 'real' world of nanotechnology. In: von Schomberg R, Davies S (eds) Understanding public debate on nanotechnologies: options for framing public policies: a working document by the services of the European Commission. European Commission, Brussels, pp 31-38

9. Sparrow R (2007) Revolutionary and familiar, inevitable and precarious: rhetorical contradictions in enthusiasm for nanotechnology. Nanoethics 1:57-68

10. Swierstra T, Rip A (2007) Nano-ethics as NEST-ethics: patterns of moral argumentation about new and emerging science and technology. Nanoethics 1:3-20

\footnotetext{
${ }^{7}$ See http://nanoriskframework.com/page.cfm?tagID $=1095$

${ }^{8}$ See: www.etcgroup.org/upload/publication/610/01/coalition letter_april07.pdf
} 